\title{
Is it possible myogenic temporomandibular dysfunctions change the facial thermal imaging?
}

\author{
Denise Sabbagh Haddad Department of Stomatology, School of Dentistry, University of São Paulo, São Paulo, Brazil • \\ Beatriz Christine de Oliveira School of Dentistry, University of São Paulo, São Paulo, Brazil • Marcos Leal Brioschi School \\ of Medicine, University of São Paulo (HCFMUSP), São Paulo, Brazil • Edgard Michel-Crosato School of Dentistry, University of \\ São Paulo, São Paulo, Brazil • Ricardo Vardasca Faculty of Engineering, University of Porto, Porto, Portugal • Joaquim Gabriel \\ Mendes Faculty of Engineering, University of Porto, Porto, Portugal • João Carlos Gonçalves Ferreira de Pinho School of Dental \\ Medicine, University of Porto, Porto, Portugal • Miguel Pais Clemente School of Dental Medicine, University of Porto, Porto, \\ Portugal • Emiko Saito Arita School of Dentistry, University of São Paulo, São Paulo, Brazil
}

ABSTRACT | Infrared thermography is a functional examination that can document physiological changes such as abnormal cutaneous vasomotor activity in inflammatory and neurogenic pictures related to nociceptive and neuropathic pain by mapping the thermal distribution on the surface of the skin. Objective: The aim of this study was to verify if there is a facial thermal difference between the symptomatic and asymptomatic group for myogenic TMD according to the Research Diagnostic Criteria for Temporomandibular Disorder (RDC/TMD) in a European population sample. Material and methods: Sixty-one subjects between 20 and 40 years ( $26.2 \pm 7.6$ years) of both sexes were divided into two groups. The 28 facial thermo-anatomic points were selected and the values of minimum (Tmin), mean (Tmed) and maximum (Tmax) temperatures, average of hemiface temperatures of whole sample, temperature difference $\left(\Delta \mathrm{T}\left({ }^{\circ} \mathrm{C}\right)\right)$ between groups and from these data an algorithm was formulated to separate the groups with greater accuracy. Results: There was an average difference of $0.3{ }^{\circ} \mathrm{C}$ of all points when comparing the two groups. The symptomatic group had lower maximum temperature for frontal and lateral views when compared to the asymptomatic group ( $p<0.05)$, and presented lower average temperature in frontal view $(p<0.05)$. Symptomatic individuals for myogenic TMD presented a reduction of facial cutaneous blood flow corresponding to lower maximum temperature by the proposed method of analysis of thermal anatomical points. Conclusions: Infrared thermography showed potential to be a screening and complementary diagnostic examination method for patients with myogenic temporomandibular disorders in the daily clinic just by frontal face image.

DESCRIPTORS | Anatomy; Face; Facial Pain; Infrared Thermography; Temporomandibular Joint.

RESUMO | É possível que disfunções temporomandibulares miogênicas alterem a imagem térmica facial? • A termografia por infravermelho é um exame funcional que pode documentar alterações fisiológicas, como atividade vasomotora cutânea anormal em quadros inflamatórios e neurogênicos relacionados à dor nociceptiva e neuropática, mapeando a distribuição térmica na superfície da pele. Objetivo: Verificar se existe diferença térmica facial entre o grupo sintomático e assintomático para DTM miogênica, de acordo com os Critérios de Diagnóstico de Pesquisa para Disfunções Temporomandibulares (RDC /TMD) em uma amostra da população europeia. Materiais e métodos: Dividiu-se 61 sujeitos entre 20 e 40 anos (26,2 \pm 7,6 anos) de ambos os sexos em dois grupos. Selecionou-se os 28 pontos termo-anatômicos faciais e os valores das temperaturas mínima (Tmin), média (Tmed) e máxima (Tmax), média das temperaturas hemifaciais de toda a amostra e a diferença de temperatura $\left(\Delta \mathrm{T}\left({ }^{\circ} \mathrm{C}\right)\right)$ entre os grupos. A partir desses dados, um algoritmo foi formulado para separar os grupos com maior precisão. Resultados: Houve diferença média de $0,3{ }^{\circ} \mathrm{C}$ em todos os pontos quando comparados os dois grupos. O grupo sintomático apresentou temperatura máxima mais baixa nas vistas frontal e lateral quando comparado ao grupo assintomático $(p<0,05)$ e apresentou temperatura média mais baixa na vista frontal ( $p 0,05)$. Indivíduos sintomáticos para DTM miogênica apresentaram redução do fluxo sanguíneo cutâneo facial correspondente à menor temperatura máxima pelo método proposto de análise de pontos anatômicos térmicos. Conclusões: A termografia por infravermelho mostrou potencial para ser um método de triagem e exame complementar de diagnóstico para pacientes com disfunção temporomandibular miogênica na clínica diária, apenas por imagem da face frontal.

DESCRITORES | Anatomia; Face; Dor Facial; Termografia por Infravermelho; Articulação Temporomandibular.

CORRESPONDING AUTHOR | - Denise Sabbagh Haddad School of Dentistry, Universidade de São Paulo • Av. Professor Lineu Prestes, 2227 São Paulo, Brazil • 05508-000 E-mail: denisesh@usp.br

- Received May 24, 2019 • Accepted Jun. 4, 2019

- Dol http://dx.doi.org/10.11606/issn.2357-8041.clrd.2019.158306 


\section{INTRODUCTION}

The number of temporomandibular dysfunction (TMD) cases has been increasing gradually in dental care facilities, as well as their comorbidities. Despite TMD being characterized by painful orofacial conditions with functional alterations involving the masticatory muscles (temporal, masseter, lateral and medial pterigoideos), temporomandibular joint (TMJ) and associated structures, ${ }^{1-3}$ its etiology is multifactorial, being associated with psychological, structural, and postural conditions that may involve the entire body and nervous system. ${ }^{1}$

Health professionals need complementary methods to aid in the diagnosis and to a better management of chronic pain due to the variable forms of TMD presentation, such as tension type headache, often associated with other painful and systemic clinical conditions. Such conditions may be degenerative diseases and anxiety states/ depression, as well as changes in the regulation of the hypothalamic-pituitary-adrenal axis (HPA) with high cortisol secretion by the adrenal cortex. ${ }^{4}$ These situations go beyond a specific dysfunction of the masticatory muscles, but also to functional changes related to the sympathetic neurovegetative system. Consequently, traditional anatomical exams such as digital radiography, computed tomography (CT) and magnetic resonance imaging (MRI) are not sufficient for research diagnosis of these related functional alterations. Therefore, methods such as Doppler ultrasonography, scintigraphy and Positron Emission Tomography (PET/CT) and digital infrared thermography have gained greater interest in scientific investigations..$^{5-10}$

Infrared thermography is a functional examination that measures, without contact, the infrared radiation emitted by the skin, registering areas of higher or lower temperature. It can document physiological changes such as: abnormal cutaneous vasomotor activity in inflammatory and neurogenic pictures related to nociceptive and neuropathic pain by mapping the thermal distribution on the surface of the skin..$^{-10}$

Human skin is considered the largest organ of the integumentary system, which is controlled by the sympathetic neurovegetative nervous system. It is a complex organ composed of several specialized structures and cell types that perform vital functions, such as thermoregulation. The hypothalamus is responsible for the regulation of body temperature by means of heat and cold receptors, which receives extrahypothalamic neural information and peripheral thermoreceptors located throughout the body. 5

Thermal studies of the Regions of interest (ROI), especially by selecting masticatory muscles and TMJ itself, were not sufficient to standardize the method and demonstrate that infrared thermography can safely be used as an isolated diagnostic medium in TMD characterization..$^{2,3,5-18}$

Recently, Haddad et al. ${ }^{5}$ defined a new protocol for the thermal evaluation of the face based on thermoanatomic points in the normal adult population, showing that these points are regular, fixed and symmetrical on the face with minimal temperature variation between individuals. These points correspond to the underlying vascularization, being this protocol able to be followed and reproduced safely.

This research aimed to verify if there is a facial thermal difference between the symptomatic and asymptomatic groups for myogenic TMD, according to the Research Diagnostic Criteria for Temporomandibular Disorder (RDC/TMD) (19), using a thermo-anatomic points protocol algorithm proposed by Haddad et al. ${ }^{5}$

\section{MATERIALS AND METHODS}

This study was carried out in accordance with the ethical standards of the Declaration of Helsinki and approved by the Research Ethics Committee of the School of Dentistry of the University of 
São Paulo (FOUSP) under No. 1.484.267, CAAE: 53725116.4.0000.0075.

Sixty-four Portuguese participants were evaluated, of both sexes, between 20 and 40 years (26.2 \pm 7.6 years). All of them had given the informed consent to participate in the study and completed a pre-assessment form that included information on current and past medical history, as well as a specific questionnaire for TMD and clinical tests and palpation as assessed by the Research Diagnostic Criteria for Temporomandibular Disorder (RDC/TMD), ${ }^{19}$ conducted by an experienced and trained professional.

The following exclusion criteria were applied: age below 18 years old, incomplete anamnesis, non-standard thermograms, previous systemic diseases such as metabolic diseases, thyroid dysfunctions and fibromyalgia syndrome, fever on the day of the exam, use of vasomotor medication, diagnosis of joint type TMD, associated or not to muscle dysfunction based on the applied RDC/ TMD result and presence of myofascial trigger point (MTP).

According to the selection criteria proposed, three cases were excluded because they presented a diagnosis of TMD joint. Therefore, all patients with a diagnosis of muscular TMD were divided into two groups: symptomatic $(\mathrm{n}=16)$ and asymptomatic control $(n=45)$ (Figure 1).

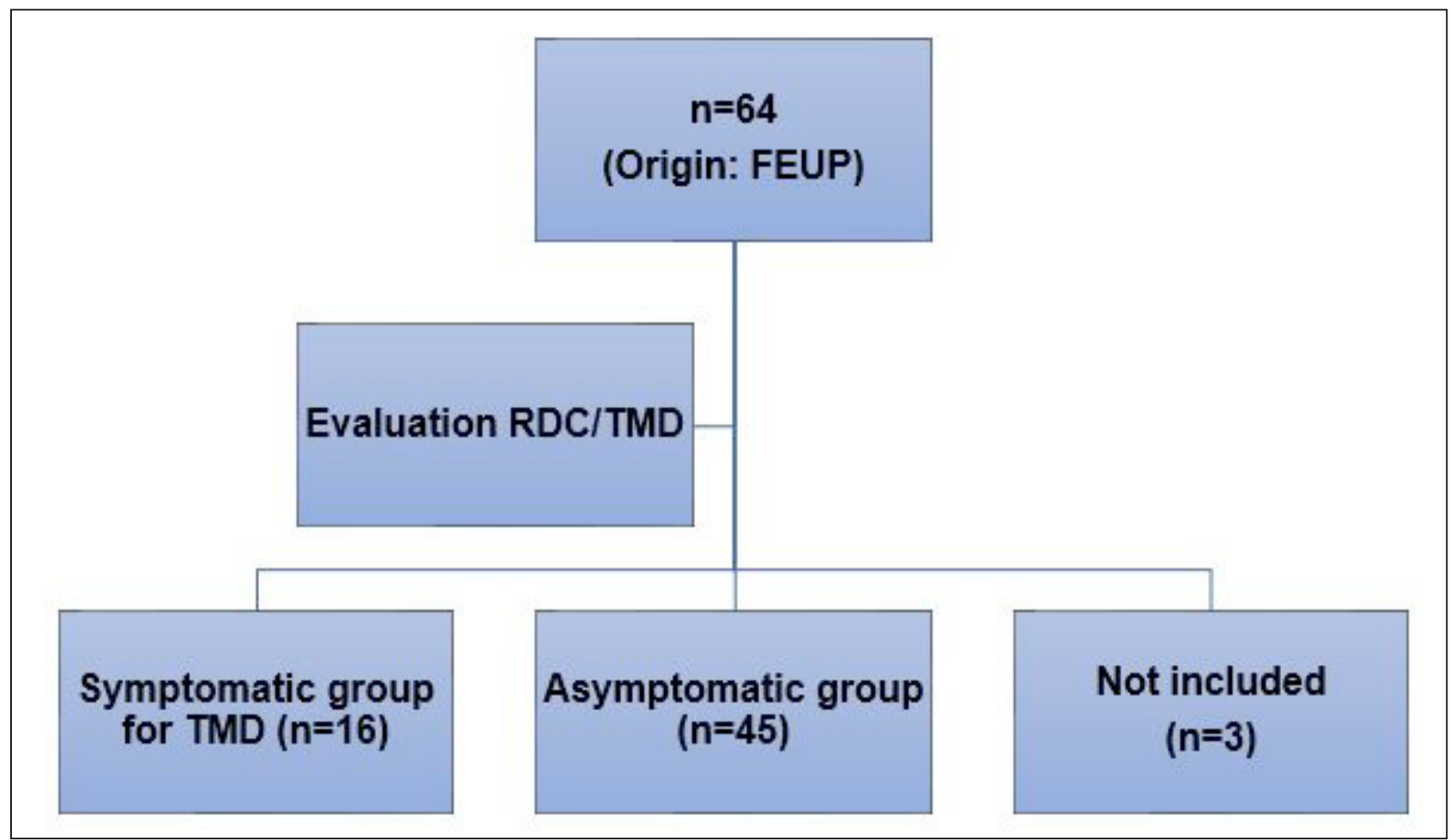

Figure 1 | Organization chart of the exclusion criteria and sample selection.

The facial thermograms were performed in three views: frontal, right and left sides (Figure 1). These thermograms were obtained by one of the authors (Denise) at the Faculty of Engineering of the University of Porto (FEUP), Portugal. For this purpose, a FLIR A325sc (FLIR Systems, Inc.,
Wilsonville, OR, USA) uncooled long wave thermal camera with focal plane sensor array size of $320 \times 240$ (76.800 pixels) with thermal sensitivity $0.05{ }^{\circ} \mathrm{C}$

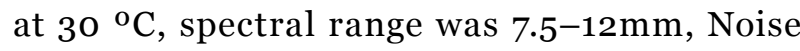
Equivalent Temperature Difference of $<50 \mathrm{OKK}$ and measurement uncertainty of $\pm 2 \%$ of the overall 
temperature range were used. The thermal images were performed respecting the international protocol recommended for the capture of medical thermographic images (20-22), with the distance between the volunteer and the machine defined as $0.84 \mathrm{~m}$; and acclimatization of the patient for 15 minutes in a controlled environment at $22 \pm 1{ }^{\circ} \mathrm{C}$ and relative humidity of $<50 \%$.

\section{Interpretation of thermograms and evaluation of data}

For the evaluation of facial thermograms, the facial protocol proposed by Haddad et al. ${ }^{5}$ was followed, consisting of the analysis of 28 thermo-anatomical reference points (Figure 2), 14 points at frontal view and 7 points at each lateral view, right and left. The distance of $0.84 \mathrm{~m}$ each point-area corresponds to $1.13 \mathrm{~cm}^{2}$.
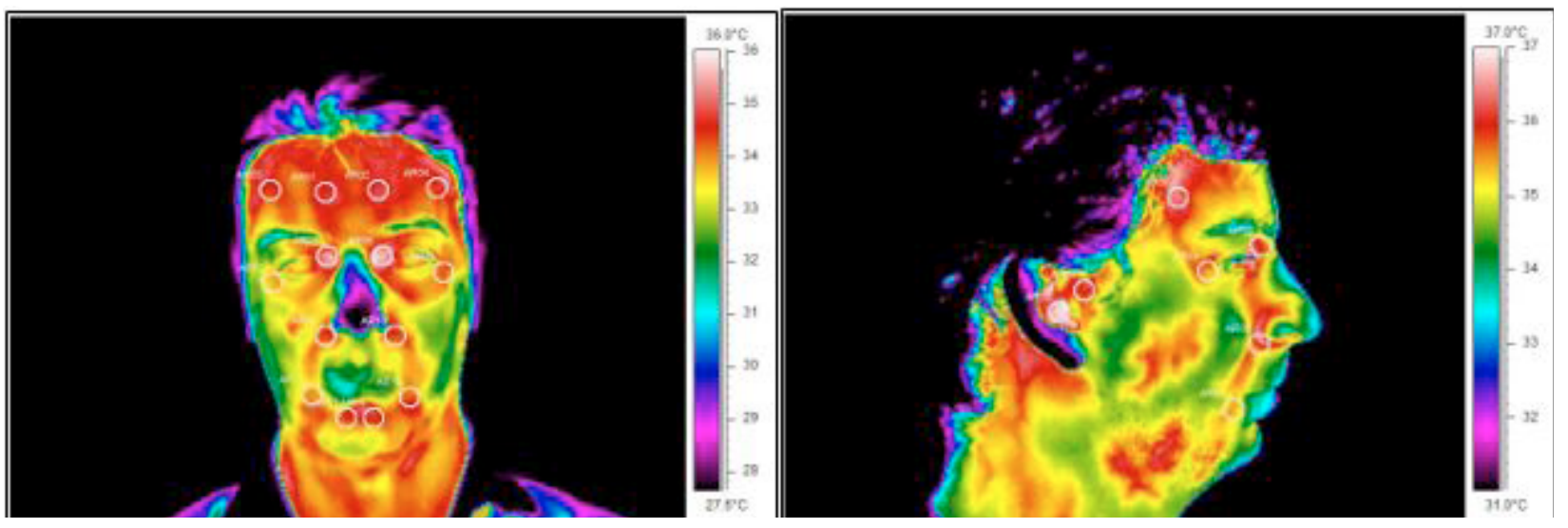

Figure 2 Lateral and frontal thermograms with all thermo-anatomical reference points (1) for evaluation. (P7 and P8), Eyelid (P7 and P8), Nasolabial (P9 and P10), Labial commissure (P7 and P8), Frontal thermogram, points: Supratroclear (P1 and P2), Temporal P11 and P12), Lower Lip (P13 and P14). (B) Lateral thermogram, points: Temporal (P1), Eyelid medial commissure (P2), Eyelid lateral commissure (P3), ATM (P4), External acoustic meatus (P5), Nasolabial (P6), Lower lip (P7).

The ThermaCAM Researcher Professional 2.10 application was used for this evaluation using the rainbow false color scale for the identification and quantification of the thermo-anatomical reference points, where the hottest spots corresponded to the white-red color and the coolest to the blue-violet color. The values of minimum (Tmin), mean (Tmean), maximum (Tmax) temperatures were obtained automatically from the ThermaCAM software. Subsequently, the temperature difference $\left(\Delta \mathrm{T}\left({ }^{\circ} \mathrm{C}\right)\right)$ for each group was calculated, and the sensitivity and specificity of the method in separating the two groups. An algorithm was formulated to increase this accuracy according to the assessed view (Equations 1, 2 and 3).

Right frontal hemiface temperature $=\frac{\mathrm{P}_{1}+\mathrm{P}_{3}+\mathrm{P}_{5}+\mathrm{P}_{7}=\mathrm{P}_{9}+\mathrm{P}_{11}+\mathrm{P}_{13}}{7}$
Left frontal hemiface temperature $=\frac{\mathrm{P}_{2}+\mathrm{P}_{4}+\mathrm{P} 6+\mathrm{P} 8+\mathrm{P} 10+\mathrm{P}_{12}+\mathrm{P}_{14}}{7}$

Left $/$ right lateral hemiface temperature $=\underline{\mathrm{P}_{1}+\mathrm{P}_{2}+\mathrm{P}_{3}+\mathrm{P}_{4}+\mathrm{P}_{5}+\mathrm{P} 6+\mathrm{P}_{7}}$

The calculations of minimum, medium and maximum temperatures were obtained automatically from the ThermaCAM software, following the facial evaluation according to the reference thermoanatomical points. According to the supposition that these points are based on thermal gradients, the authors excluded the minimum temperature of all the analyzes. After obtaining the temperatures, the average maximum and average temperatures for each hemiface were calculated according to formulas 1, 2 and 3 in both frontal (Tables 2 and 3) and lateral (Tables 4 and 5) views. Two types of analysis were performed. First, the Pearson's 
coefficient was evaluated between the temperatures obtained from the symptomatic and asymptomatic groups for myogenic TMD. In the second, the ROC curve was calculated for the mean and maximum temperatures obtained with the results of the palpation examination (with or without pain) of the studied muscles: temporal, upper masseter, medium masseter and lower masseter. It is important to note that the muscles with myofascial trigger point were removed from the sample.

For statistical analysis, the STATA program (R Core Team, 2014) was used, in which the t-Student test, Pearson correlation and Receiver Operating Characteristic Curve (ROC) were calculated to determine the temperature cutoff values for each area according to the group.

\section{RESULTS}

The selected sample with and without a diagnosis of muscular TMD corresponded to 61 cases, with ages ranging from 20-40 years (26.2 \pm 7.6 years) and $67 \%$ of them were females. The frequency of the facial thermo-anatomical reference points corresponded to $96 \%$. The sample was divided into two groups according to the applied RDC/TMD: asymptomatic $(\mathrm{n}=45)$ and sy mptomatic $(\mathrm{n}=16)$. When comparing the groups according to sex and age, no statistical significance was found ( $p>0.05$ ) (Table 1).

Table 1 | Descriptive analysis of the sample.

\begin{tabular}{c|c|c|c|c|}
\hline & & Without TMD $(n=45)$ & With TMD $(n=16)$ & $p$ \\
\hline \multirow{2}{*}{ Sex } & Female $(n=41)-67.2 \%$ & $26 / 41(63.4 \%)$ & $15 / 43(34.9 \%)$ & 0.064 \\
\cline { 2 - 5 } & Male $(n=20)-32.8 \%$ & $18 / 20(90 \%)$ & $2 / 21(9.5 \%)$ & \\
\hline Age & Year & $25.6 \pm 6.5$ & $27.9 \pm 10.2$ & 0.273 \\
\hline
\end{tabular}

Comparing the frontal view, the symptomatic group had a lower maximum temperature (Tmax) (range from $34.71^{\circ} \mathrm{C}$ to $34.84^{\circ} \mathrm{C}$ ) when compared to the asymptomatic group (range from $35.11^{\circ} \mathrm{C}$ to 35.21 $\left.{ }^{\circ} \mathrm{C}\right)(p<0.05)$ (Table 2). The same trend occurred with the mean temperature (Tmean): the symptomatic group (range from $34.30^{\circ} \mathrm{C}$ to $34.42^{\circ} \mathrm{C}$ ) presented lower temperature than the asymptomatic group (range from $34.74^{\circ} \mathrm{C}$ to $\left.34.85^{\circ} \mathrm{C}\right)(p<0.05)$ (Table 3$)$. The temperature difference between the symptomatic and asymptomatic groups $\left(\Delta \mathrm{T}\left({ }^{\circ} \mathrm{C}\right)\right)$ was equal to or greater than $0.3^{\circ} \mathrm{C}$ in all evaluations performed (Tables 2 and 3 ).

Table 2 | Mean of the maximum temperatures (Tmax) of the thermo-anatomical reference points, between the groups, by the frontal view.

\begin{tabular}{c|c|c|c|c}
\hline Muscles & $\begin{array}{c}\text { Asymptomatic group } \\
\text { (Tmax) }\end{array}$ & $\begin{array}{c}\text { Symptomatic group } \\
\text { (Tmax) }\end{array}$ & $p$ & $\Delta \mathrm{T}\left({ }^{\circ} \mathrm{C}\right)$ \\
\hline Temporal & $35.12 \pm 0.54$ & $34.82 \pm 0.40$ & 0.001 & 0.30 \\
\hline Upper Masseter & $35.18 \pm 0.52$ & $34.71 \pm 0.39$ & $<0.001$ & 0.37 \\
\hline Medial Masseter & $35.21 \pm 0.51$ & $34.84 \pm 0.44$ & $<0.001$ & 0.37 \\
\hline Lower Masseter & $35.21 \pm 0.50$ & $34.84 \pm 0.47$ & $<0.001$ & 0.37 \\
\hline
\end{tabular}


Table 3 | Mean of the averaged temperatures (Tmed) of the thermo-anatomical reference points, between the groups, by the frontal view.

\begin{tabular}{c|c|c|c|}
\hline Muscles & $\begin{array}{c}\text { Asymptomatic group } \\
\text { (Tmax) }\end{array}$ & $\begin{array}{c}\text { Symptomatic group } \\
\text { (Tmax) }\end{array}$ & $\begin{array}{c}\mathrm{p}\left({ }^{\circ} \mathrm{C}\right) \\
\text { Temporal }\end{array}$ \\
\hline Upper Masseter & $34.74 \pm 0.56$ & $34.41 \pm 0.45$ & 0.001 \\
\hline Medial Masseter & $34.83 \pm 0.54$ & $34.30 \pm 0.43$ & 0.001 \\
\hline Lower Masseter & $34.85 \pm 0.52$ & $34.42 \pm 0.49$ & 0.001 \\
\hline
\end{tabular}

Among the asymptomatic groups (between $35.38^{\circ} \mathrm{C}$ and $35.45^{\circ} \mathrm{C}$ ) and symptomatic (variation between $35.10^{\circ} \mathrm{C}$ and $35.25^{\circ} \mathrm{C}$ ), there was a statistical difference only in the maximum temperature
(Tmax) (Tables 4 and 5) according to the areas of the involved muscles $(p<0.05)$. However, most of the differences between the right and left hemiface $\left(\Delta \mathrm{T}\left({ }^{\circ} \mathrm{C}\right)\right)$ were lower or very close to $0.3^{\circ} \mathrm{C}$.

Table 4 | Mean of the maximum temperatures (Tmax) of the thermo-anatomical reference points, between the groups, by lateral view.

\begin{tabular}{|c|c|c|c|c|}
\hline Muscles & Asymptomatic group (Tmax) & $\begin{array}{l}\text { Symptomatic group } \\
\text { (Tmax) }\end{array}$ & $\mathrm{p}$ & $\Delta \mathrm{T}\left({ }^{\circ} \mathrm{C}\right)$ \\
\hline Temporal & $35.38 \pm 0.52$ & $35.18 \pm 0.37$ & $<0.05$ & 0.20 \\
\hline Upper Masseter & $35.43 \pm 0.51$ & $35.10 \pm 0.38$ & $<0.001$ & 0.33 \\
\hline Medial Masseter & $35.45 \pm 0.52$ & $35.20 \pm 0.38$ & $<0.05$ & 0.25 \\
\hline Lower Masseter & $35.44 \pm 0.50$ & $35.25 v 0.41$ & $<0.05$ & 0.19 \\
\hline
\end{tabular}

Table 5 | Mean of the average temperatures (Tmean) of the thermo-anatomical reference points, between the groups, by lateral view.

\begin{tabular}{|c|c|c|c|c|}
\hline Muscles & Asymptomatic group (Tmax) & $\begin{array}{c}\text { Symptomatic group } \\
\text { (Tmax) }\end{array}$ & $\mathrm{p}$ & $\Delta \mathrm{T}\left({ }^{\circ} \mathrm{C}\right)$ \\
\hline Temporal & $34.78 \pm 0.52$ & $34.71 \pm 0.53$ & 0.523 & 0.07 \\
\hline Upper Masseter & $34.80 \pm 0.50$ & $34.66 \pm 0.52$ & 0.164 & 0.14 \\
\hline Medial Masseter & $34.81 \pm 0.51$ & $34.75 \pm 0.51$ & 0.553 & 0.06 \\
\hline Lower Masseter & $34.81 \pm 0.51$ & $34.74 \pm 0.49$ & 0.509 & 0.07 \\
\hline
\end{tabular}

The mean and maxium temperatures obtained by the ROC curve presented satisfactory performance (AUC > 0.73) with acut-off value $>34.5^{\circ} \mathrm{C}$ and high correlation $(r=0.94)$ for maximum and average temperatures (Figure 3). 


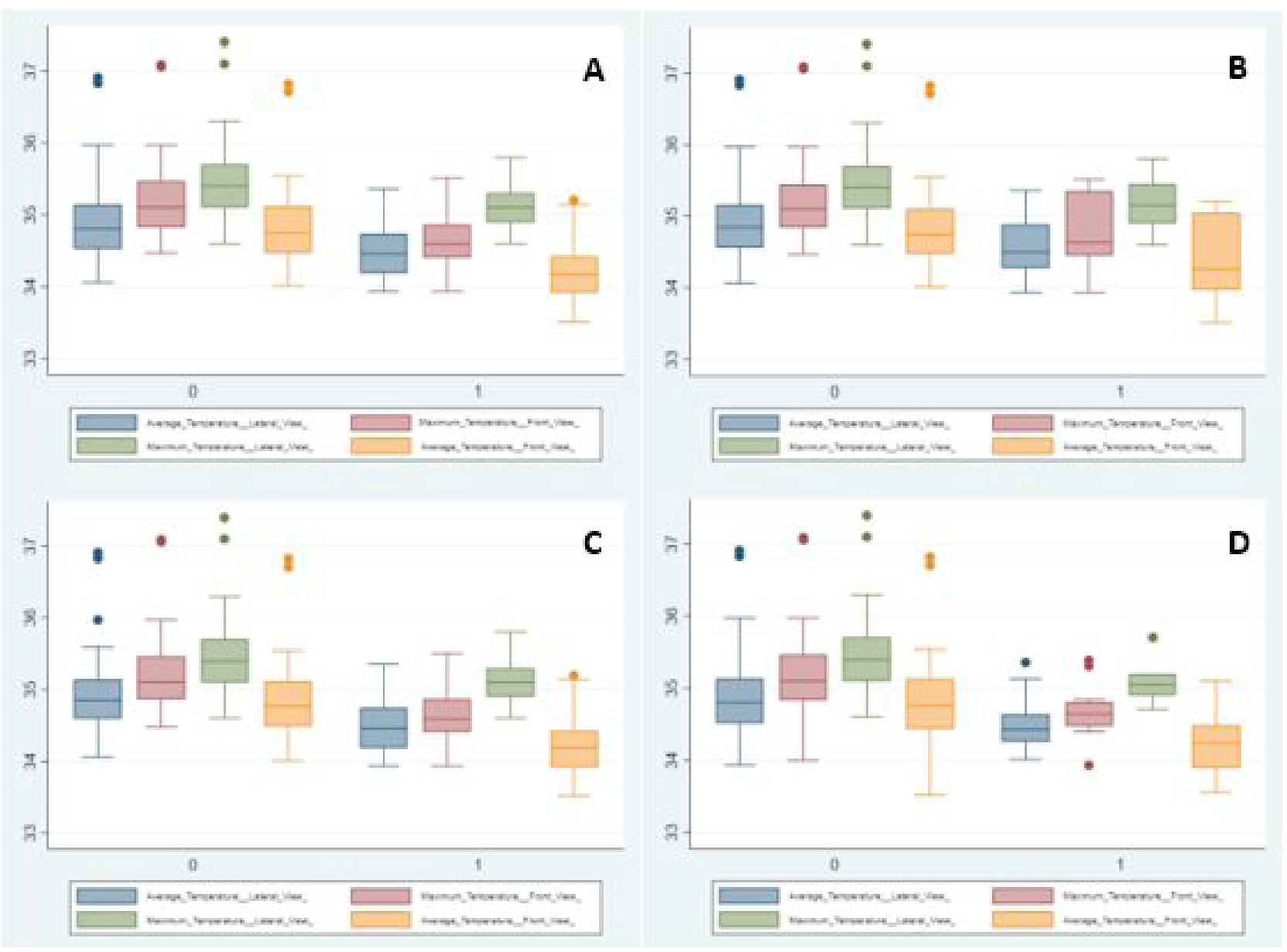

Figure 3 | Comparative boxplot of the mean and maximum temperatures by the proposed method, from the frontal and lateral views between the asymptomatic (0) and symptomatic (1) groups. A- Temporal muscle area evaluated with and without painful palpation symptomatology; B- upper masseter muscle area evaluated with and without painful palpation symptomatology; C- area of the medial masseter muscle evaluated with and without painful palpation symptomatology; D- area of lower masseter muscle evaluated with and without painful palpation symptomatology.

\section{DISCUSSION}

This research project suggests that individuals with muscular TMD show decreased face temperature due to reduced cutaneous blood flow when compared to asymptomatic individuals, using the thermo-anatomic points methodology proposed by Haddad et al. ${ }^{5}$

In this study, young volunteers of both sexes with and without myogenic TMD were included. Age and sex did not seem to have influence in the results, since there was no statistical evidence of difference between the groups.

The diagnostic documentation of muscular type TMD most accepted so far is through the Research
Diagnostic Criteria for Temporomandibular Disorder (RDC/TMD) - axis I, which included questionnaires and physical examination as supporting instruments. ${ }^{19}$ Traditional anatomical imaging methods do not meet the clinical criteria of RDC/ TMD, due to the fact that they are not functional exams for muscle analysis, the main component of TMD. Many research projects, ${ }^{3,5,9,10,12-18}$ have already suggested the possibility of using functional methods, among them infrared thermography. Infrared thermal imaging is a functional mean to evaluate myogenic TMD, with the advantage of being a painless and non-invasive examination, and could be easily applied in the daily clinic and in mass 
screening of this problem. ${ }^{2,3,5-18}$ Considering that it does not use ionizing radiation and it is a rapid and non-invasive examination, infrared thermography has been much studied in the area of chronic pain in recent years. ${ }^{3,5,9,10,12-18,23}$

Skin temperature is directly related to the blood flow controlled by the sympathetic vasomotor system. The temperature control affects both sides of the body evenly and simultaneously, resulting in a very symmetrical thermal pattern. ${ }^{2,3,5-18}$ However, the cutaneous surface can temperature be influenced by internal and external factors, ${ }^{22}$ such as the circadian rhythm, caloric consumption, physical activity, emotional state, relative air humidity and atmospheric temperature. Therefore, it is always necessary to control these variables as much as possible through specific guidelines, such as the one used in this study to obtain comparable results. ${ }^{20-22}$

The thermographic examination can reflect the microcirculatory dynamics of the region studied accurately measuring the body surface temperature by capturing infrared thermal images in high resolution and in real time. Although, despite a number of studies in dental Thermology have been published in recent years, these studies do not demonstrate a standardized descriptive evaluation of facial perfusion regarding TMD. ${ }^{2,3,6,10,12-18}$ To the best of authors' knowledge, this is the first research using a facial protocol of thermo-anatomic points that aims to evaluate group of patients with and without myogenic TMD, using a thermal evaluation according to cutaneous microcirculation.

Uematsu et al., ${ }^{24}$ in 1988 , were the first ones to document the thermal symmetry between the right and left anatomical locations of the normal asymptomatic human body, including the face. According to several authors, values above $0.3^{\circ} \mathrm{C}(\Delta \mathrm{T})$ are already indicative of abnormality, especially in patients with temporomandibular dysfunction. . $3,3,6,7,9,13$ The results of this research were concordant with the literature when comparing symptomatic and asymptomatic groups for TMD $\left(\Delta \mathrm{T}>0.3^{\circ} \mathrm{C}, p<0.05\right)$, as well as the maximum and average temperature, but only for the frontal view $(\mathrm{r}=0.94)$. This seems to facilitate mass evaluation by just one image, the frontal view. There was no statistical evidence of difference in the lateral view $\left(\Delta \mathrm{T} \leq 0.3^{\circ} \mathrm{C}, p>0.05\right)$. This can be explained because the frontal region of the face is more pronounced than the lateral view, so the difference becomes more evident when there are abnormal vasomotor repercussions.

It is reported that hypoxia caused by muscle contraction may be a factor that triggers a cutaneous sympathetic vasomotor hyperactivity accompanied by pain or not, which is observed both on the masticatory muscle projection ${ }^{9,10}$ and on the hemiface as a whole. ${ }^{5}$ Consequently, the thermal pattern shows a local temperature reduction due to vasoconstriction of the regional skin microcirculation. This dysfunction usually occurs unilaterally or more clearly on one side than on the another, generating an often asymmetric pattern, as in this study. Because of this, the temperature difference $\left(\Delta \mathrm{T}\left({ }^{\circ} \mathrm{C}\right)\right)$ occurs between the affected and unaffected (or less affected side).

Although, it was found a temperature decrease in accordance with other study, ${ }^{9,12,14}$ which describe a thermal pattern with temperature increase characterized by hyper-radiation. ${ }^{13,15-18}$ In part, this controversy may be due to the lack of standardization of protocols for facial analysis and, consequently, to the comparison of different areas of interest (ROI), regarding both location and size, as well as the lack of standardization in image acquisition distance. Additionally, by ROIs on symptomatic MTP, which was not the scope of this study. Even so, the authors carefully evaluate the presence or not of MTP in the masticatory muscles during palpation and excluded all the muscles that presented them.

In this research, a methodology already described in the literature was used, ${ }^{5}$ aiming to discover an 
algorithm to be used in muscle TMDs and to identify individuals with TMD regardless of previous palpation. These results results, therefore, show that symptomatic individuals with myogenic TMD present cutaneous reduction of blood flow from the frontal view $(p<0.05)$ when compared to the asymptomatic group, whether using maximum or mean temperature.

As cutaneous temperature is a direct function of cutaneous blood flow controlled by the sympathetic neurovegetative system, in the tensioned muscle and in pain, the local microcirculation is reduced and, consequently, the cutaneous surface temperature may be reflecting this condition. ${ }^{9,12,14}$ Wozniak et al. ${ }^{25}$ suggested including a chewing test to increase the diagnostic efficiency of thermography in identifying patients with TMD.

Due to the size of this sample, there was no statistical evidence of significant difference in relation to the separation of the TMD groups regarding mild, moderate or severe intensity ( $p>$ 0.05). However, even though promising, it was only possible to separate individuals with or without myogenic TMD. From the results obtained, the thermal pattern of facial temperature reduction in individuals with muscle type TMD is a consequence of a reflex sympathetic vasomotor response caused by myofascial somatic stimulus.

The changes in individuals with TMD are better shown when measuring the maximum temperature from the frontal view. It is suggested that for this type of TMD study, the thermal evaluation of the whole face should be considered, and not only small areas that reflect the region of the altered muscles. The authors believe that the combination of temperature points/areas of the entire face can help diagnose TMD better than the adjacent TMJ and masticatory muscles, and that data could be classified with artificial intelligence systems through machine learning algorithms, which could improve this proposed methodology.

\section{CONCLUSIONS}

Symptomatic individuals with myogenic TMD presented a reduction of facial cutaneous blood flow corresponding to lower maximum temperature by the proposed method of thermo-anatomic points analysis. Infrared thermography has shown the potential to be used for screening and complementary diagnostic examination of patients with myogenic temporomandibular disorders in the daily clinical practice through imaging the frontal face.

\section{REFERENCES}

1. Leeuw R, Klasser GD, editors. Orofacial pain: guidelines for assessment, diagnosis and management. $5^{\text {th }}$ ed. Chicago: Quintessence; 2013.

2. Gratt BM, Pullinger A, Sickles EA, Lee JJ. Electronic thermography of normal facial structures: a pilot study. Oral Surg Oral Med Oral Pathol Oral Radiol. 1989;68(3):346-51. doi: 10.1016/0030-4220(89)90222-3.

3. Johansson A, Kopp S, Haraldson T. Reproducibility and variation of skin surface temperature over the temporomandibular joint and masseter muscle in normal individuals. Acta Odontol Scand. 1985;43(5):309-13.

4. Staniszewski K, Lygre H, Bifulco E, Kvinnsland S, Willassen L, Helgeland E, et al. Temporomandibular disorders related to stress and HPA-axis regulation. Pain Res Manag. 2018;2018:1-7. doi: 10.1155/2018/7020751.

5. Haddad DS, Brioschi ML, Baladi MG, Arita ES. A new evaluation of heat distribution on facial skin surface by infrared thermography. Dentomaxillofac Radiol. 2016;45(4):20150264. doi: 10.1259/dmfr.20150264.

6. Gratt BM, Sickles EA. Thermographic characterization of the asymptomatic temporomandibular joint. J Orofac Pain. 1993;7(1):7-14.

7. Gratt BM, Sickles EA. Electronic facial thermography: an analysis of asymptomatic adult subjects. J Orofac Pain. 1995;9(3):255-65.

8. Christensen J, Vaeth M, Wenzel A. Thermographic imaging of facial skin - gender differences and temperature changes over time in healthy subjects. Dentomaxillofac Radiol. 2012;41(8):662-7. doi: 10.1259/dmfr/55922484.

9. Haddad DS, Brioschi ML, Vardasca R, Weber M, Crosato EM, Arita ES. Thermographic characterization of masticatory muscle regions in volunteers with and without myogenous tempo- 
romandibular disorder: preliminary results. Dentomaxillofac Radiol. 2014;43(8):20130440. doi: 10.1259/dmfr.20130440.

10. Haddad DS, Brioschi ML, Arita ES. Thermographic and clinical correlation of myofascial trigger points in the masticatory muscles. Dentomaxillofac Radiol. 2012;41(8):621-9. doi: 10.1259/dmfr/98504520.

11. Weinstein SA, Weinstein G, Weinstein EL, Gelb M. Facial thermography, basis, protocol, and clinical value. Cranio. 1991;9(3):201-11. doi: 10.1080/o8869634.1991.11678368.

12. Dibai-Filho AV, Packer AC, Costa AC, Rodrigues-Bigaton $\mathrm{D}$. The chronicity of myogenous temporomandibular disorder changes the skin temperature over the anterior temporalis muscle. J Bodyw Mov Ther. 2014;18(3):430-4. doi: 10.1016/j.jbmt.2013.11.001.

13. Canavan D, Gratt BM. Electronic thermography for the assessment of mild and moderate temporomandibular joint dysfunction. Oral Surg Oral Med Oral Pathol Oral Radiol. 1995;79(6):778-86.

14. Barão VA, Gallo AK, Zuim PR, Garcia AR, Assunção WG. Effect of occlusal splint treatment on the temperature of different muscles in patients with TMD. J Prosthodont Res. 2011;55(1):19-23.

15. Kawano W, Kawazoe T, Tanaka M, Hikida Y. Deep thermometry of temporomandibular joint and masticatory muscle regions. J Prosthet Dent. 1993;69(2):216-21.

16. Berry DC, Yemm R. Variations in skin temperature of the face in normal subjects and in patients with temporomandibular dysfunction. Br J Oral Surg. 1971;8(3):242-7. 10.1016/Sooo7117X(70)80086-5

17. Berry DC, Yemm R. A further study of facial skin temperature in patients with mandibular dysfunction. J Oral Rehabil. 1974;1(3):255-64.

18. Pogrel MA, Erbez G, Taylor RC, Dodson TB. Liquid crystal thermography as a diagnostic aid and objective monitor for TMJ dysfunction and myogenic facial pain. J Craniomandib Disord. 1989;3(2):65-70.

19. Dworkin SF, LeResche L. Research diagnostic criteria for temporomandibular disorders: review, criteria, examinations and specifications, critique. J Craniomandib Disord. 1992;6(4):301-55.

20. Schwartz RG. Guidelines For Dental-Oral And Systemic Health Infrared Thermography - 2019 Edition. Pan American J Med Thermol. 2018;5:41-55. doi: http://dx.doi. org/10.18073/2358-4696/pajmt.v5n1p41-55

21. Ring EFJ, Ammer K. The technique of infrared imaging in medicine. Thermol. int. 2000;10(1):7-14. doi: 10.1088/978o-7503-1143-4ch1.
22. Ammer K. Influence of imaging and object conditions on temperature readings from medical infrared images. Polish J of Environ. Stud. 2006;15(4A):117-9.

23. Antonaci F, Rossi E, Voiticovschi-Iosob C, Volta GD, Marceglia S. Frontal infrared thermography in healthy individuals and chronic migraine patients: Reliability of the method. Cephalalgia. 2019;39(4):489-96. doi: 10.1177/0333102418788341.

24. Uematsu S, Edwin DH, Jankel WR, Kozikowski J, Trattner M. Quantification of thermal asymmetry. Part 1: normal values and reproducibility. J Neurosurg. 1988;69(4):552-5. doi: 10.3171/jns.1988.69.4.0552.

25. Woźniak K, Szyszka-Sommerfeld L, Trybek G, Piątkowska D. Assessment of the sensitivity, specificity, and accuracy of thermography in identifying patients with TMD. Med Sci Monit. 2015;21:1485-93. doi: 10.12659/MSM.893863. 